\title{
One additional shot of brachial plexus block equates to less postoperative pain for younger children with elbow surgeries
}

\author{
Jin Li', Saroj Rai ${ }^{2}$, Ruikang Liư ${ }^{3}$, Ruijing $\mathrm{Xu}^{1}$ and Pan Hong ${ }^{1 *}$ (D)
}

\begin{abstract}
Background: Postoperative pain in children has always been inadequately evaluated. This study aims to evaluate the postoperative pain response using an additional dose of brachial plexus block (BPB) for younger children receiving elbow surgeries under general anesthesia (GA).

Methods: This retrospective case-control study included pediatric patients (3-10 years) who underwent surgeries for elbow injuries between January 2015 and January 2019. Patients with previous history of surgeries around the elbow, neurological impairment of injured limb, polytrauma, undergoing pain management for different causes, and open or old fractures were excluded. Patients were dichotomized into the GA group and the GA + BPB group as per the presence or absence of BPB.

Results: In all, 150 patients (102/48, male/female) in the GA and 150 patients (104/46, male/female) in the GA + BPB group were included. There existed no significant differences between the two groups in age, sex, fracture side, and types of elbow procedures. As for the pain response after lateral condyle fracture of the humerus (LCFH), the FLACC pain scale was significantly higher for those in the GA group $(6.2 \pm 0.8)$ when compared to the GA + BPB group (1.6 \pm 0.5$)(P<0.001)$. As for the pain response after medial epicondyle fracture of the humerus (MCFH), the FLACC pain scale was significantly higher for those in the GA group (6.0 \pm 0.8$)$ when compared to the GA + BPB group $(1.5 \pm 0.5)(P<0.001)$. As for the pain response after supracondylar fracture of the humerus $(\mathrm{SCFH})$, the FLACC pain scale was significantly higher for those in the GA group ( $6.0 \pm 0.8)$ when compared to the GA + BPB group $(1.6 \pm 0.5)(P<0.001)$. As for the pain response after cubitus varus correction, the FLACC pain scale was significantly higher for those in the GA group $(6.7 \pm 0.7)$ when compared to the GA + BPB group $(2.1 \pm 0.7)(P<$ 0.001)
\end{abstract}

Conclusion: An additional shot of BPB for patients undergoing surgeries for elbow surgeries resulted in better postoperative pain response in younger children without significant BPB-related complications.

Keywords: Brachial plexus block, General anesthesia, Postoperative pain, Children

\footnotetext{
* Correspondence: hongpan2013@foxmail.com

'Department of Orthopaedic Surgery, Union Hospital, Tongji Medical College, Huazhong University of Science and Technology, Wuhan 430022, China

Full list of author information is available at the end of the article
}

(C) The Author(s). 2020 Open Access This article is licensed under a Creative Commons Attribution 4.0 International License, which permits use, sharing, adaptation, distribution and reproduction in any medium or format, as long as you give appropriate credit to the original author(s) and the source, provide a link to the Creative Commons licence, and indicate if changes were made. The images or other third party material in this article are included in the article's Creative Commons licence, unless indicated otherwise in a credit line to the material. If material is not included in the article's Creative Commons licence and your intended use is not permitted by statutory regulation or exceeds the permitted use, you will need to obtain permission directly from the copyright holder. To view a copy of this licence, visit http://creativecommons.org/licenses/by/4.0/ The Creative Commons Public Domain Dedication waiver (http://creativecommons.org/publicdomain/zero/1.0/) applies to the data made available in this article, unless otherwise stated in a credit line to the data. 


\section{Background}

Most of the orthopedic surgeries in the pediatric population, especially in younger children, are performed under general anesthesia (GA) [1]. Age less than 10 years is considered as a young child at our institute, and usually, GA is chosen as the anesthetic modality for such patients. However, postoperative pain in children has always been inadequately evaluated [2, 3]. Healthcare workers (HCWs) in the postanesthesia care unit (PACU) and residents on night shift always complain about the difficulties tackling with crying and screaming kids in pain $[4,5]$. However, pain management is influenced by many factors, such as cultural values, religions, parental beliefs, and anxiety [6, 7]. Besides, the description of pain provided by the children is usually inconclusive [8]. Several non-pharmacological methods, including position adjustment, reassurance [9], and music, have been proposed to alleviate the pain [10-12].

In order to cope with postoperative pain, additional ultrasonography (US)-guided brachial plexus block (BPB) was implemented for pediatric patients under GA since 2017 at our institute. This study aims to compare the postoperative pain response under GA with or without $\mathrm{BPB}$ retrospectively.

\section{Methods}

From January 2015 to January 2019, all patients who underwent elbow surgeries under GA were retrospectively reviewed. Since 2017, additional BPB was performed in younger children at our institute, and it was consented by the parents. The results are summarized according to the type of fractures that the patient had: lateral condylar fracture of the humerus (LCFH), medial epicondyle fracture of the humerus $(\mathrm{MCFH})$, supracondylar fracture of the humerus (SCFH), and cubitus varus deformity.

Inclusion criteria: (1) pediatric patients aged between 3 and 10 years who underwent surgeries for LCFH, $\mathrm{MCFH}, \mathrm{SCFH}$, and corrective osteotomy and fixation for cubitus varus deformity; (2) no previous history of surgeries around the same elbow; and (3) patients without neurological impairment. Exclusion criteria: (1) patients with polytrauma or open fractures, (2) patients with the underlying disease requiring regular pain management, (3) patients not having clear and complete medical records, and (4) delayed presentation of elbow fractures.

The pain response at PACU after extubation was evaluated by the anesthetic nurse using Face, Legs, Activity, Cry, and Consolability (FLACC) pain scale [13]. Pain response in the ward on the first night after surgery was reported by the patient using the Faces Pain ScaleRevised (FPS-R) [14], by the caregiver using the numeric rating scale (NRS) [15], and by the on-call nurse using the FLACC pain scale. Baseline information, including sex, age, operative side, procedures, and application of a tourniquet, was recorded and reviewed.

SPSS statistical package program (SPSS 19.0 version; SPSS Inc., Chicago, Illinois, USA) was used for statistical analysis. The categorical data were analyzed using the chi-square $\left(\chi^{2}\right)$ test, and the continuous data were analyzed using Student's $t$ test. Fisher exact test was used under those circumstances with fewer subjects in groups of interest. Data were presented as mean \pm SD (range), median (range), or $n$ (\%). A $P$ value of less than 0.05 was considered significantly different.

\section{Result}

As shown in Table 1, 150 patients (102/48, male/female) in the GA and 150 patients (104/46, male/female) in the GA + BPB group were included in our study. There existed no significant difference between the two groups regarding age, sex, fracture side, and types of procedures.

As for the pain response after LCFH (Table 2), there were 44 patients $(34 / 10$, male/female) in the GA group and 45 patients $(35 / 10$, male/female) in the GA + BPB group. There existed no significant difference between the two groups concerning age, sex, fracture side, duration of surgery, and application of a tourniquet. The FLACC pain scale was significantly higher for those in the GA group $(6.2 \pm 0.8)$ when compared to the GA + BPB group $(1.6 \pm 0.5)(P<0.001)$, and all patients in GA group were given additional analgesics in PACU. The pain response from the patient, caregiver, and $\mathrm{HCW}$ was significantly better in the GA + BPB group. The frequency of waking up from the sleep, calling nurse/doctor, and utilization of oral ibuprofen was significantly higher in the GA group than the GA + BPB group. Thirty-nine percent (17/44) of patients in the GA group required additional analgesics during the night shift, whereas only $8.9 \%(4 / 45)$ in the $\mathrm{GA}+\mathrm{BPB}$ group required additional analgesics.

As for the pain response after MCFH (Table 3), there were 23 patients $(18 / 5$, male/female) in the GA group

Table 1 Demographic and clinical parameters of children with elbow injuries

\begin{tabular}{llll}
\hline Parameters & GA $(n=150)$ & GA + BPB $(n=150)$ & $P$ value \\
\hline Age, years & $7.2 \pm 1.9$ & $7.5 \pm 1.7$ & 0.152 \\
Sex, male/female & $102 / 48$ & $104 / 46$ & 0.803 \\
Fracture side, L/R & $95 / 55$ & $92 / 58$ & 0.721 \\
LC & $44(29.3 \%)$ & $45(30.0 \%)$ & 0.998 \\
ME & $23(15.3 \%)$ & $23(15.3 \%)$ & \\
SC & $60(40.0 \%)$ & $60(40.0 \%)$ & \\
CV & $23(15.3 \%)$ & $22(14.7 \%)$ & \\
\hline
\end{tabular}

GA general anesthesia, $B P B$ brachial plexus block, $L C$ lateral condyle fracture, $M E$ medial epicondyle fracture, SC supracondylar fracture, $C V$ cubitus varus deformity

Data shown as mean \pm SD or $n(\%)$ 
Table 2 Pain response in children with LC

\begin{tabular}{|c|c|c|c|c|}
\hline \multicolumn{2}{|l|}{ Parameters } & $\mathrm{GA}(n=44)$ & $\mathrm{GA}+\mathrm{BPB}(n=45)$ & $P$ value \\
\hline \multicolumn{2}{|l|}{ Age, years } & $7.2 \pm 1.8$ & $7.2 \pm 1.8$ & 0.964 \\
\hline \multicolumn{2}{|l|}{ Sex, male/female } & $34 / 10$ & $35 / 10$ & 0.834 \\
\hline \multicolumn{2}{|l|}{ Fracture side, L/R } & $34 / 10$ & $32 / 13$ & 0.498 \\
\hline \multicolumn{2}{|l|}{ Duration of surgery, min } & $49.6 \pm 6.7$ & $48.9 \pm 7.0$ & 0.633 \\
\hline \multicolumn{2}{|l|}{ Tourniquet } & 0 & 0 & $>0.999$ \\
\hline \multicolumn{2}{|l|}{ FLACC in PACU } & $6.2 \pm 0.8$ & $1.6 \pm 0.5$ & $<0.001^{*}$ \\
\hline \multicolumn{2}{|l|}{ Analgesic in PACU } & $44(100 \%)$ & 0 & $<0.001^{\star}$ \\
\hline \multicolumn{2}{|l|}{ FPS-R, patient } & $5.1 \pm 1.0$ & $3.4 \pm 1.0$ & $<0.001^{*}$ \\
\hline \multicolumn{2}{|l|}{ NRS, caregiver } & $3.8 \pm 0.8$ & $2.3 \pm 0.5$ & $<0.001^{*}$ \\
\hline \multicolumn{2}{|l|}{ FLACC in ward } & $3.1 \pm 0.9$ & $1.9 \pm 0.5$ & $<0.001^{*}$ \\
\hline \multirow[t]{4}{*}{ Wake from sleeping, times } & 0 & 0 & $27(60.0 \%)$ & \multirow[t]{4}{*}{$<0.001^{*}$} \\
\hline & 1 & 0 & $7(15.6 \%)$ & \\
\hline & 2 & $10(22.7 \%)$ & $11(24.4 \%)$ & \\
\hline & $\geq 3$ & $34(87.3 \%)$ & 0 & \\
\hline \multirow[t]{4}{*}{ Call nurse/doctor, times } & 0 & $9(20.5 \%)$ & $24(53.3 \%)$ & \multirow[t]{4}{*}{$<0.001^{*}$} \\
\hline & 1 & $6(13.6 \%)$ & $14(31.1 \%)$ & \\
\hline & 2 & $16(36.4 \%)$ & $7(15.6 \%)$ & \\
\hline & $\geq 3$ & $13(29.5 \%)$ & 0 & \\
\hline \multirow[t]{4}{*}{ Oral ibuprofen, times } & 0 & 0 & $45(100 \%)$ & \multirow[t]{4}{*}{$<0.001^{*}$} \\
\hline & 1 & 0 & 0 & \\
\hline & 2 & 19 (43.2\%) & 0 & \\
\hline & $\geq 3$ & $25(56.8 \%)$ & 0 & \\
\hline \multicolumn{2}{|l|}{ Additional analgesic } & $17(38.6 \%)$ & $4(8.9 \%)$ & $<0.001^{*}$ \\
\hline
\end{tabular}

PACU postanesthesia care unit; FLACC Face, Leg, Activity, Cry, and Consolability; FPS-R Faces Pain Scale-Revised; NRS numeric rate scale Data shown as mean \pm SD or $n(\%)$ $*<0.05$

and 23 patients $(18 / 5$, male/female) in the GA + BPB group. There existed no significant difference between the two groups concerning age, sex, fracture side, duration of surgery, and application of a tourniquet. The FLACC pain scale was significantly higher for those in the GA group $(6.0 \pm 0.8)$ when compared to the GA + BPB group $(1.5 \pm 0.5)(P<0.001)$, and all patients in the GA group required additional analgesics in PACU. The pain response from the patient, caregiver, and $\mathrm{HCW}$ was significantly better in the GA + BPB group. The frequency of waking up from the sleep, calling nurse/doctor, and utilization of oral ibuprofen was significantly higher in the GA than the GA + BPB. Fifty-two percent $(12 / 23)$ of patients in the GA group required additional analgesics during the night shift, whereas only 13\% (3/ $23)$ in the GA + BPB group required additional analgesics.

As for the pain response after SCFH (see Fig. 1, Table 4), there were 60 patients $(38 / 22$, male/female) in the GA group and 60 patients (36/24, male/female) in the GA + BPB group. There existed no significant difference between the two groups concerning age, sex, fracture side, duration of surgery, and application of a tourniquet. The FLACC pain scale was significantly higher for those in the GA group $(6.0 \pm 0.8)$ than the GA + BPB group $(1.6 \pm 0.5)(P<$ $0.001)$, and $75.0 \%(45 / 60)$ patients in GA group required additional analgesics in PACU. The pain response from the patient, caregiver, and HCW was significantly better in the GA + BPB group. The frequency of waking up from the sleep, calling nurse/doctor, and utilization of oral ibuprofen was significantly higher in the GA group than the GA + BPB group. Twenty-five percent (15/60) of patients in the GA group required additional analgesics during the night shift, whereas no patients in the GA + BPB group required additional analgesics.

As for the pain response after corrective osteotomy for cubitus varus deformity (Table 5), there were 23 patients $(12 / 11$, male/female) in the GA group and 22 patients (15/7, male/female) in the GA + BPB group. There existed no significant difference between the two groups concerning age, sex, fracture side, duration of surgery, and application of a tourniquet. The FLACC pain scale was significantly higher for those in the GA group (6.7 \pm $0.7)$ when compared to the GA + BPB group $(2.1 \pm 0.7)$ 
Table 3 Pain response in children with medial epicondyle fractures

\begin{tabular}{|c|c|c|c|c|}
\hline \multicolumn{2}{|l|}{ Parameters } & $\mathrm{GA}(n=23)$ & $\mathrm{GA}+\mathrm{BPB}(n=23)$ & $P$ value \\
\hline \multicolumn{2}{|l|}{ Age, years } & $7.9 \pm 1.2$ & $8.5 \pm 1.0$ & 0.073 \\
\hline \multicolumn{2}{|l|}{ Sex, male/female } & $18 / 5$ & $18 / 5$ & $>0.999$ \\
\hline \multicolumn{2}{|l|}{ Fracture side, $L / R$} & $10 / 13$ & $9 / 14$ & 0.925 \\
\hline \multicolumn{2}{|l|}{ Duration of surgery, min } & $45.4 \pm 8.3$ & $43.9 \pm 8.2$ & 0.533 \\
\hline \multicolumn{2}{|l|}{ Tourniquet } & 0 & 0 & $>0.99$ \\
\hline \multicolumn{2}{|l|}{ FLACC in PACU } & $6.0 \pm 0.8$ & $1.5 \pm 0.5$ & $<0.001^{*}$ \\
\hline \multicolumn{2}{|l|}{ Analgesic in PACU } & $23(100 \%)$ & 0 & $<0.001^{*}$ \\
\hline \multicolumn{2}{|l|}{ FPS-R, patient } & $5.0 \pm 1.0$ & $3.1 \pm 1.0$ & $<0.001^{*}$ \\
\hline \multicolumn{2}{|l|}{ NRS, caregiver } & $4.0 \pm 0.8$ & $2.5 \pm 0.5$ & $<0.001^{*}$ \\
\hline \multicolumn{2}{|l|}{ FLACC in ward } & $3.2 \pm 0.7$ & $2.0 \pm 0.6$ & $<0.001^{*}$ \\
\hline \multirow[t]{4}{*}{ Wake from sleeping, times } & 0 & 0 & $10(43.5 \%)$ & \multirow[t]{4}{*}{$<0.001^{*}$} \\
\hline & 1 & 0 & $6(26.1 \%)$ & \\
\hline & 2 & $6(26.1 \%)$ & 7 (30.4\%) & \\
\hline & $\geq 3$ & $17(73.9 \%)$ & 0 & \\
\hline \multirow[t]{4}{*}{ Call nurse/doctor, times } & 0 & $1(4.3 \%)$ & $10(43.5 \%)$ & \multirow[t]{4}{*}{$0.002^{*}$} \\
\hline & 1 & 9 (39.1\%) & $10(43.5 \%)$ & \\
\hline & 2 & $10(43.5 \%)$ & $3(13.0 \%)$ & \\
\hline & $\geq 3$ & $3(13.0 \%)$ & 0 & \\
\hline \multirow[t]{4}{*}{ Oral ibuprofen, times } & 0 & 0 & $23(100 \%)$ & \multirow[t]{4}{*}{$<0.001^{*}$} \\
\hline & 1 & 0 & 0 & \\
\hline & 2 & $12(52.2 \%)$ & 0 & \\
\hline & $\geq 3$ & $11(47.8 \%)$ & 0 & \\
\hline \multicolumn{2}{|l|}{ Additional analgesic } & $12(52.2 \%)$ & $3(13.0 \%)$ & $0.005^{*}$ \\
\hline
\end{tabular}

PACU postanesthesia care unit; FLACC Face, Leg, Activity, Cry, and Consolability; FPS-R Faces Pain Scale-Revised; NRS numeric rate scale Data shown as mean $\pm \mathrm{SD}$ or $n(\%)$ ${ }^{*}<0.05$

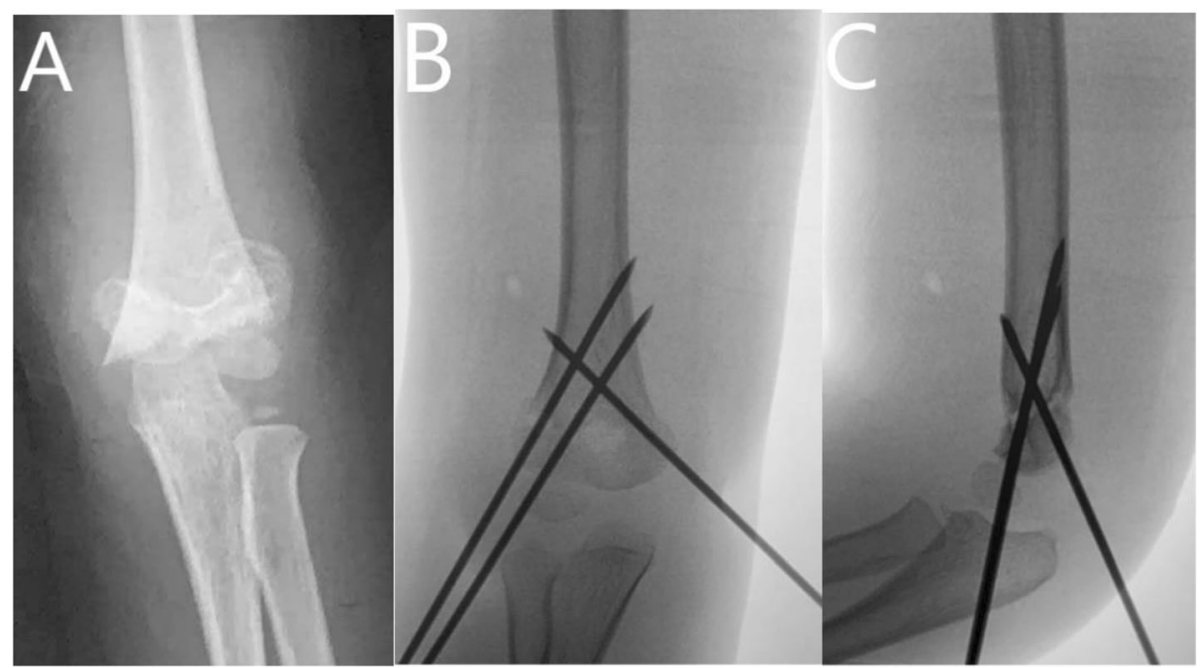

Fig. 1 A 7-year boy of left supracondylar fracture treated with CRPP. a AP view of the elbow before the surgery. b AP view of the elbow after surgery. c Lateral view of the elbow after surgery 
Table 4 Pain response in children with supracondylar fractures

\begin{tabular}{|c|c|c|c|c|}
\hline \multicolumn{2}{|l|}{ Parameters } & $\mathrm{GA}(n=60)$ & $\mathrm{GA}+\mathrm{BPB}(n=60)$ & $P$ value \\
\hline \multicolumn{2}{|l|}{ Age, years } & $6.4 \pm 1.9$ & $7.5 \pm 1.7$ & $0.002^{*}$ \\
\hline \multicolumn{2}{|l|}{ Sex, male/female } & $38 / 22$ & $36 / 24$ & 0.658 \\
\hline \multicolumn{2}{|l|}{ Fracture side, L/R } & $35 / 25$ & $35 / 25$ & $>0.999$ \\
\hline \multicolumn{2}{|l|}{ Duration of surgery, min } & $44.0 \pm 9.2$ & $43.5 \pm 7.9$ & 0.752 \\
\hline \multicolumn{2}{|l|}{ Tourniquet } & 0 & 0 & $>0.999$ \\
\hline \multicolumn{2}{|l|}{ FLACC in PACU } & $6.0 \pm 0.8$ & $1.6 \pm 0.5$ & $<0.001^{*}$ \\
\hline \multicolumn{2}{|l|}{ Analgesic in PACU } & $45(75.0 \%)$ & 0 & $<0.001^{*}$ \\
\hline \multicolumn{2}{|l|}{ FPS-R, patient } & $5.6 \pm 1.1$ & $3.4 \pm 1.0$ & $<0.001^{*}$ \\
\hline \multicolumn{2}{|l|}{ NRS, caregiver } & $4.1 \pm 0.8$ & $2.4 \pm 0.5$ & $<0.001^{*}$ \\
\hline \multicolumn{2}{|l|}{ FLACC in ward } & $3.1 \pm 0.9$ & $1.9 \pm 0.6$ & $<0.001^{*}$ \\
\hline \multirow[t]{4}{*}{ Wake from sleeping, times } & 0 & 0 & $28(46.7 \%)$ & \multirow[t]{4}{*}{$<0.001^{*}$} \\
\hline & 1 & $27(45.0 \%)$ & $21(35.0 \%)$ & \\
\hline & 2 & $26(43.3 \%)$ & $11(18.3 \%)$ & \\
\hline & $\geq 3$ & $7(11.7 \%)$ & 0 & \\
\hline \multirow[t]{4}{*}{ Call nurse/doctor, times } & 0 & $25(41.7 \%)$ & $36(60.0 \%)$ & \multirow[t]{4}{*}{0.067} \\
\hline & 1 & $17(28.3 \%)$ & $16(26.7 \%)$ & \\
\hline & 2 & $15(25.0 \%)$ & $8(13.3 \%)$ & \\
\hline & $\geq 3$ & $3(5.0 \%)$ & 0 & \\
\hline \multirow[t]{4}{*}{ Oral ibuprofen, times } & 0 & 0 & 60 (100\%) & \multirow[t]{4}{*}{$<0.001^{*}$} \\
\hline & 1 & $44(73.3 \%)$ & 0 & \\
\hline & 2 & $16(26.7 \%)$ & 0 & \\
\hline & $\geq 3$ & 0 & 0 & \\
\hline \multicolumn{2}{|l|}{ Additional analgesic } & $15(25.0 \%)$ & 0 & $<0.001^{*}$ \\
\hline
\end{tabular}

PACU postanesthesia care unit; FLACC Face, Leg, Activity, Cry, and Consolability; FPS-R Faces Pain Scale-Revised; NRS numeric rate scale Data shown as mean $\pm \mathrm{SD}$ or $n(\%)$ $*<0.05$

$(P<0.001)$, and all patients in GA group required additional analgesics, whereas $54.5 \%(12 / 22)$ in the GA + $\mathrm{BPB}$ group required analgesics in PACU. The pain response from the patient, caregiver, and $\mathrm{HCW}$ was significantly better in the GA + BPB group. The frequency of waking up from the sleep, calling nurse/doctor, and utilization of oral ibuprofen was significantly higher in the GA group than the GA + BPB group. Seventy-four percent $(17 / 23)$ of patients in the GA group required additional analgesics during the night shift, whereas only $27.3 \%(6 / 22)$ in the GA + BPB group required additional analgesics.

None of the patients reported BPB-related complications during the postoperative follow-up visit.

\section{Discussion}

Additional BPB for elbow surgeries resulted in better postoperative pain response without significant BPBrelated complications.

Elbow surgeries for fractures and cubitus varus deformity correction are common in the pediatric population [16, 17]. Although clinical outcomes of surgeries following fractures around the elbow are usually satisfactory, however, postoperative pain management remains challenging $[2,5,6]$. Pain is a significant parameter influencing recovery, early mobilization, and hospital stay [18]. BPB is an effective choice in the management of shoulder or humeral surgery in children [19-22]. Guidance with ultrasonography (US) improves the accuracy of needle advancement and anatomic identification of neural structures [23]. Although US-guided BPB is gaining popularity in the pediatric population [24, 25], the application of BPB in younger kids is still limited [26]. In our hospital, GA remains the preferred choice in pediatric surgeries. However, the results of this study indicated that the GA + $\mathrm{BPB}$ was more effective in reducing the pain following surgeries around the elbow.

In displaced $\mathrm{LCFH}$ and $\mathrm{MCFH}$, open reduction and internal fixation (ORIF) is our preferred choice and usually yields satisfactory outcomes $[27,28]$. Whereas, closed reduction and percutaneous pinning (CRPP) remains the primary choice for displaced SCFH [29]. Regardless of the fracture type and operative choice, the pain response was significantly lower in the GA + BPB group in our study. However, some patients receiving GA + BPB for corrective osteotomy and fixation for cubitus varus 
Table 5 Pain response in children with cubitus varus

\begin{tabular}{|c|c|c|c|c|}
\hline \multicolumn{2}{|l|}{ Parameters } & $\mathrm{GA}(n=23)$ & $\mathrm{GA}+\mathrm{BPB}(n=22)$ & $P$ value \\
\hline \multicolumn{2}{|l|}{ Age, years } & $8.3 \pm 1.4$ & $6.8 \pm 1.8$ & $0.004^{*}$ \\
\hline \multicolumn{2}{|l|}{ Sex, male/female } & $12 / 11$ & $15 / 7$ & 0.128 \\
\hline \multicolumn{2}{|l|}{ Fracture side, L/R } & $16 / 7$ & $16 / 6$ & 0.843 \\
\hline \multicolumn{2}{|l|}{ Duration of surgery, min } & $58.6 \pm 6.1$ & $61.8 \pm 6.3$ & 0.097 \\
\hline \multicolumn{2}{|l|}{ Tourniquet } & $23(100 \%)$ & $22(100 \%)$ & $>0.99$ \\
\hline \multicolumn{2}{|l|}{ FLACC in PACU } & $6.7 \pm 0.7$ & $2.1 \pm 0.7$ & $<0.001^{*}$ \\
\hline \multicolumn{2}{|l|}{ Analgesic in PACU } & $23(100 \%)$ & $12(54.5 \%)$ & $<0.001^{*}$ \\
\hline \multicolumn{2}{|l|}{ FPS-R, patient } & $5.5 \pm 0.8$ & $3.9 \pm 1.1$ & $<0.001^{*}$ \\
\hline \multicolumn{2}{|l|}{ NRS, caregiver } & $4.8 \pm 0.5$ & $2.7 \pm 0.5$ & $<0.001^{*}$ \\
\hline \multicolumn{2}{|l|}{ FLACC in ward } & $3.9 \pm 0.7$ & $2.1 \pm 0.7$ & $<0.001^{*}$ \\
\hline \multirow[t]{4}{*}{ Wake from sleeping, times } & 0 & 0 & $3(13.6 \%)$ & \multirow[t]{4}{*}{$<0.001^{*}$} \\
\hline & 1 & 0 & $7(31.8 \%)$ & \\
\hline & 2 & $4(17.4 \%)$ & $12(54.5 \%)$ & \\
\hline & $\geq 3$ & 19 (82.6\%) & 0 & \\
\hline \multirow[t]{4}{*}{ Call nurse/doctor, times } & 0 & $2(8.7 \%)$ & $10(45.5 \%)$ & \multirow[t]{4}{*}{$0.002^{*}$} \\
\hline & 1 & $7(30.4 \%)$ & $10(45.5 \%)$ & \\
\hline & 2 & $8(34.8 \%)$ & $2(9.1 \%)$ & \\
\hline & $\geq 3$ & $6(26.1 \%)$ & 0 & \\
\hline \multirow[t]{4}{*}{ Oral ibuprofen, times } & 0 & 0 & $4(18.2 \%)$ & \multirow[t]{4}{*}{$<0.001^{*}$} \\
\hline & 1 & 0 & 9 (40.9\%) & \\
\hline & 2 & $6(26.1 \%)$ & $9(40.9 \%)$ & \\
\hline & $\geq 3$ & 17 (73.9\%) & 0 & \\
\hline \multicolumn{2}{|l|}{ Additional analgesic } & 17 (73.9\%) & $6(27.3 \%)$ & $<0.001^{*}$ \\
\hline
\end{tabular}

PACU postanesthesia care unit; FLACC Face, Leg, Activity, Cry, and Consolability; FPS- $R$ Faces Pain Scale-Revised; NRS numeric rate scale Data shown as mean \pm SD or $n(\%)$

$*<0.05$

deformity complained of significant pain, possibly due to the application of a tourniquet.

Additionally, the cost for BPB is about 120 US dollars at our institute, and it is affordable for most patients and their families. There have been reports regarding the complications, including pneumothorax and neuropathy, related to the BPB [30, 31]; however, no BPB-related complications were apparent on the second postoperative day in our study.

An additional BPB is recommended for patients undergoing ORIF for elbow fractures; however, it might not be necessary for patients requiring CRPP only. More attention should be paid for postoperative pain management for patients undergoing corrective osteotomy and fixation with the application of a tourniquet for cubitus varus deformity. It is because the corrective osteotomy and fixation usually takes longer surgical time and prolonged use of the tourniquet that might result in tourniquet-related pain [32, 33].

There were certain limitations in our study. Firstly, it is a retrospective study with modest sample size; secondly, the cost of BPB is different in different countries, and cost-effective analysis remains to be investigated.

\section{Conclusion}

An additional shot of BPB for patients undergoing surgeries for elbow surgeries resulted in better postoperative pain response in younger children without significant BPB-related complications. Those treated with GA + BPB had significantly less pain regardless of the fracture type. Patients treated with GA + BPB also woke up from sleep much less and utilized oral ibuprofen significantly less than those treated with GA alone regardless of fracture type.

\footnotetext{
Abbreviations

HCW: Healthcare worker; GA: General anesthesia; PACU: Postanesthesia care unit; BPB: Brachial plexus block; FLACC: Face, Leg, Activity, Cry, and Consolability pain scale; FPS-R: Faces Pain Scale-Revised; NRS: Numeric rate scale; ORIF: Open reduction and internal fixation; CRPP: Closed reduction and percutaneous pinning
}

\section{Acknowledgements}

Not applicable.

\section{Authors' contributions}

$\mathrm{PH}^{*}$ is in charge of the main idea and is the guarantor of integrity of the entire clinical study; $\lrcorner$ and $\mathrm{PH}$ are in charge of the study concepts, design, manuscript preparation, and editing; $\mathrm{PH}$ and SR are in charge of the language polishing and the grammar revision; RKL and RJX are in charge of 
the collection of the study data. All authors read and approved the final manuscript.

\section{Funding}

None.

\section{Availability of data and materials}

The datasets supporting the conclusion of this article are included within the article. Upon request, raw data can be provided by the corresponding author.

\section{Ethics approval and consent to participate}

Not applicable. Since this study was a retrospective investigation, the Ethics Committee of Tongji Medical College, Huazhong University of Science and Technology ruled that no formal ethics approval was required. Written consents to participate in this study were obtained from the legal guardians of every patient

\section{Consent for publication}

Written consents were obtained from the legal guardians of every patient for publication of this paper.

\section{Competing interests}

The authors declare that they have no competing interests.

\section{Author details}

'Department of Orthopaedic Surgery, Union Hospital, Tongji Medical College, Huazhong University of Science and Technology, Wuhan 430022, China. ${ }^{2}$ Department of Orthopaedics and Trauma Surgery, National Trauma Center, National Academy of Medical Sciences, Mahankal, Kathmandu, Nepal. ${ }^{3}$ First School of Clinical Medicine, Tongji Medical College, Huazhong University of Science and Technology, Wuhan, China.

Received: 21 April 2020 Accepted: 30 June 2020

Published online: 06 July 2020

\section{References}

1. Mellon RD, Simone AF, Rappaport BA. Use of anesthetic agents in neonates and young children. Anesth Analg. 2007;104(3):509-20.

2. Rømsing J, Møller-Sonnergaard J, Hertel S, Rasmussen M. Postoperative pain in children: comparison between ratings of children and nurses. J Pain Symptom Manage. 1996;11(1):42-6.

3. Hamers JP, Abu-Saad HH, van den Hout MA, Halfens RJ. Are children given insufficient pain-relieving medication postoperatively? J Adv Nurs. 1998; 27(1):37-44.

4. Moyer SM, Howe CJ. Pediatric pain intervention in the PACU. Crit Care Nurs Clin North Am. 1991:3(1):49-57.

5. Rheiner JG, Megel ME, Hiatt M, Halbach R, Cyronek DA, Quinn J. Nurses' assessments and management of pain in children having orthopedic surgery. Issues Compr Pediatr Nurs. 1998;21(1):1-18.

6. Chieng YJ, Chan WC, Klainin-Yobas P, He HG. Perioperative anxiety and postoperative pain in children and adolescents undergoing elective surgical procedures: a quantitative systematic review. J Adv Nurs. 2014;70(2):243-55.

7. Joestlein L. Pain, pain, go away! Evidence-based review of developmentally appropriate pain assessment for children in a postoperative setting. Orthop Nurs. 2015;34(5):252-61.

8. Mesko PJ, Eliades AB. Using pictures to assess pain location in children. $J$ Perianesth Nurs. 2018:33(3):319-24.

9. Makhlouf MM, Garibay ER, Jenkins BN, Kain ZN, Fortier MA. Postoperative pain: factors and tools to improve pain management in children. Pain Manag. 2019;9(4):389-97.

10. Olsen SW, Rosenkilde C, Lauridsen J, Hasfeldt D. Effects of nonpharmacologic distraction methods on children's postoperative pain-a nonmatched case-control study. J Perianesth Nurs. 2020;35(2):147-54.

11. Kavak Akelma F, Altınsoy S, Arslan MT, Ergil J. Effect of favorite music on postoperative anxiety and pain. Wirkung von Lieblingsmusik auf postoperative Angst und Schmerz. Anaesthesist. 2020;69(3):198-204.

12. Lin $\mathrm{CL}$, Hwang $\mathrm{SL}$, Jiang $\mathrm{P}$, Hsiung $\mathrm{NH}$. Effect of music therapy on pain after orthopedic surgery-a systematic review and meta-analysis. Pain Pract. 2020; 20(4):422-36.
13. Chambers $C T$, Giesbrecht K, Craig KD, Bennett SM, Huntsman E. A comparison of faces scales for the measurement of pediatric pain: children's and parents' ratings. Pain. 1999;83:25.

14. Hicks CL, von Baeyer C, Spafford PA, van Korlaar I, Goodenough B. The faces pain scale-revised: toward a common metric in pediatric pain measurement. Pain. 2001;93:173-83.

15. Voepel-Lewis T, Malviya S, Tait AR, et al. A comparison of the clinical utility of pain assessment tools for children with cognitive impairment. Anesth Analg. 2008;106:72-8.

16. Li J, Rai S, Tang X, Ze R, Liu R, Hong P. Surgical management of delayed Gartland type III supracondylar humeral fractures in children: a retrospective comparison of radial external fixator and crossed pinning. Medicine (Baltimore). 2020;99(10):e19449.

17. Tang $X$, Wang J, Slongo $T$, et al. Comparison of internal fixation vs. external fixation after corrective osteotomy in children with cubitus varus. J Shoulder Elbow Surg. 2020;29(4):845-52.

18. Touray ST, de Leeuw MA, Zuurmond WW, Perez RS. Psoas compartment block for lower extremity surgery: a meta-analysis. Br J Anaesth. 2008;101(6):750-60.

19. Gerrard C, Roberts S. Ultrasound-guided regional anaesthesia in the paediatric population. ISRN Anesthesiol. 2012:1-7.

20. Delvi MB. Ultrasound-guided peripheral and truncal blocks in pediatric patients. Saudi J Anaesth. 2011:5(2):208-16.

21. Lee J-H, Kim Y-R, Yu H-K, Cho S-H, Kim S-H, Chae WS. Ultrasound-guided interscalene brachial plexus block in a pediatric patient with acute hepatitis - a case report. Korean J Anesthesiol. 2012;62(6):568-70.

22. Ecoffey C. Safety in pediatric regional anesthesia. PediatrAnesth. 2012;22(1):25-30.

23. Ganesh A, Gurnaney HG. Ultrasound guidance for pediatric peripheral nerve blockade. Anesthesiol Clin. 2009;27(2):197-212.

24. Yayik AM, Cesur S, Öztürk F, Celik EC, Ahiskalioglu A. Ultrasound guided costoclavicular approach to brachial plexus: first pediatric report. J Clin Anesth. 2019:55:136-7.

25. Xu C, Wang B, Yang A, et al. The efficacy of pediatric ultrasound guided brachial plexus block anesthesia and determination of optimal anesthetic drug dosage [published online ahead of print, 2016 Nov 9]. Minerva Pediatr. 2016.

26. Yanal H, Gürkan Y, Kuş A, Balaban O, Solak M, Toker K. Awake hand surgery under ultrasound-guided infraclavicular block is possible for cooperative children. Agri. 2016:28(4):190-3.

27. Tomori Y, Nanno M, Takai S. Posteromedial elbow dislocation with lateral humeral condylar fracture in children: three case reports and a literature review. Medicine (Baltimore). 2018;97(36):e12182.

28. Su Y, Nan G. Treatment of medial humeral epicondyle fractures in children using absorbable self-reinforced polylactide pins. Medicine (Baltimore). 2020; 99(17):e19861.

29. Okubo H, Nakasone M, Kinjo M, Onaka K, Futenma C, Kanaya F. Epidemiology of paediatric elbow fractures: a retrospective multi-centre study of 488 fractures. J Child Orthop. 2019;13(5):516-21.

30. Russell HG, Tsao JW. Phantom sensations following brachial plexus nerve block: a case report. Front Neurol. 2018;9:436.

31. Gupta A, Talwar V, Kamal G, Gupta N. Delayed onset and prolonged Horner syndrome in two children after single-shot ultrasound guided infraclavicular and subclavian perivascular brachial plexus blocks for upper extremity surgery: case reports. AANA J. 2019;87(4):313-6.

32. Inal S, Er M, Ozsoy M, Cavusoglu A, Dincel V, Sakaogullari A. Comparison of two different anesthesia techniques for tourniquet pain with the use of forearm tourniquet. lowa Orthop J. 2009;29:55-9.

33. Crews JC, Cahall MA. An investigation of the neurophysiologic mechanisms of tourniquet-related pain: changes in spontaneous activity and receptive field size in spinal dorsal horn neurons. Reg Anesth Pain Med. 1999;24(2):102-9.

\section{Publisher's Note}

Springer Nature remains neutral with regard to jurisdictional claims in published maps and institutional affiliations. 